\title{
Multi-gas sensor to detect simultaneously nitrogen oxides and oxygen
}

\author{
Julia Herrmann ${ }^{1}$, Gunter Hagen ${ }^{1}$, Jaroslaw Kita ${ }^{1}$, Frank Noack ${ }^{2}$, Dirk Bleicker ${ }^{2}$, and Ralf Moos ${ }^{1}$ \\ ${ }^{1}$ Department of Functional Materials, Bayreuth Engine Research Center (BERC), University of Bayreuth, \\ Bayreuth 95440, Germany \\ ${ }^{2}$ CPK Automotive GmbH \& Co. KG, Münster 48157, Germany \\ Correspondence: Ralf Moos (funktionsmaterialien@uni-bayreuth.de)
}

Received: 15 April 2020 - Revised: 31 July 2020 - Accepted: 14 August 2020 - Published: 9 October 2020

\begin{abstract}
Due to tightened emission limits, the efficiency of exhaust gas aftertreatment systems has to be further enhanced. Therefore, inexpensive and robust $\mathrm{NO}_{x}$ sensors are required to be installed not only in automotive exhausts, but also in any other kind of combustion-based application. In this contribution, an impedimetric $\mathrm{NO}_{x}$ sensor is presented. The impedance of a functional thick film $\left(\mathrm{KMnO}_{4}\right.$, manufactured in a screenprinting technique on planar alumina substrates) depends selectively on the $\mathrm{NO}_{x}$ concentration in the exhaust but shows a dependency on the oxygen concentration. Therefore, an additional temperature-independent resistive oxygen sensor structure was integrated on the same sensor platform. BFAT $\left(\mathrm{BaFe}_{0.74} \mathrm{Al}_{0.01} \mathrm{Ta}_{0.25} \mathrm{O}_{3-\delta}\right.$ $\left(\mathrm{BaFe}_{0.74} \mathrm{Al}_{0.01} \mathrm{Ta}_{0.25} \mathrm{O}_{3-\delta}\right)$ was used for this purpose, and the measurement was conducted in the dc resistance mode. It serves not only to determine the oxygen concentration in the exhaust, but also to correct the oxygen dependency of the $\mathrm{NO}_{x}$ sensor.
\end{abstract}

\section{Introduction}

The emission limits for nitrogen oxides from combustion exhausts are becoming increasingly tightened over time. Various concepts exist to abate nitrogen oxide $\left(\mathrm{NO}_{x}\right)$ emissions by exhaust gas aftertreatment (Deutschmann and Grunwaldt, 2013). Monitoring such systems requires robust sensors. Commercially available $\mathrm{NO}_{x}$ sensors are based on zirconium oxide and comprise a complex three-dimensional setup with several chambers, diffusion areas, and electrodes. They are manufactured in complex high-temperature co-fired ceramics technology (HTCC) and are not inexpensive devices (van Basshuysen, 2002). Their sensor signal is only in the $\mu \mathrm{A}$ range, and they show a pronounced $\mathrm{NH}_{3}$ crosssensitivity. As a cost-effective alternative, recently, an impedimetric $\mathrm{NO}_{x}$ sensor was suggested. Typical $\mathrm{NO}_{x}$ storage materials are used as functional materials. These materials form nitrates and nitrites under $\mathrm{NO}_{x}$ impact. The chemical transformation leads to a change in the material properties (Groß, 2016; Yao and Shelef, 1973). So that NO can be sorbed at the functional layer, it is first converted into
$\mathrm{NO}_{2}$ with $\mathrm{O}_{2}$. In the second step, the $\mathrm{NO}_{2}$ is stored as nitrate in an oxygen-rich atmosphere over several oxidation steps. Consequently, sufficient oxygen must be available for the storage of nitrogen oxides (Groß, 2016; Roy and Baiker, 2009; Groß et al., 2012). If the sensor is operated at higher temperature, above $600^{\circ} \mathrm{C}$, the adsorption and desorption of the nitrogen oxides are in equilibrium. Groß (2016) investigated the properties of $\mathrm{NO}_{x}$ storage materials like barium carbonate and potassium carbonate as pure materials as well as deposited on manganese oxide or cerium oxide. It was shown that potassium carbonate deposited on manganese oxide provided the best sensor behavior. Further work (Lattus et al., 2018) confirmed the suitability of the material as a high-temperature $\mathrm{NO}_{x}$ gas sensor. If the sensor is operated at temperatures below $600^{\circ} \mathrm{C}$, the material shows the typical storage behavior known from exhaust gas aftertreatment systems. Especially in the range from 300 to $400^{\circ} \mathrm{C}$, the sensor shows a non-reversible $\mathrm{NO}_{x}$ storage in the form of nitrates. In this temperature range, the adsorption of nitrogen oxides predominates over their desorption. Thus, another possibility is to operate the sensor in low-temperature ranges as an 
accumulative gas sensor, also called a gas dosimeter. More detailed information on gas dosimeters can be found in Marr and Moos (2017), Groß (2016), Marr (2016), and Groß et al. (2013). In the context of this study, the sensor shall be operated as a classical concentration sensor. For this reason, an operating temperature of $650{ }^{\circ} \mathrm{C}$ and a film of potassium permanganate $\left(\mathrm{KMnO}_{4}\right)$ supported on lanthanum-stabilized $\gamma-\mathrm{Al}_{2} \mathrm{O}_{3}$ as functional materials are used.

In further studies it was found that the $\mathrm{NO}_{x}$-dependent characteristics also depend on the oxygen content. Lower oxygen concentrations lead not only to a lower resistivity of the sensor material, but also to a lower sensitivity towards $\mathrm{NO}_{x}$. Hagen et al. (2019) suggested that an additional oxygen signal may help to overcome this problem: $\mathrm{NO}_{x}$ characteristic curves were taken in the lab under different oxygen and $\mathrm{NO}_{x}$ concentrations. They were used to correct the $\mathrm{NO}_{x}$ sensor signal by considering the particular oxygen concentration. By that, the evaluation of dynamically changing $\mathrm{NO}_{x}$ and real diesel exhaust should be possible (Hagen et al., 2019).

To be able to determine the influence of oxygen on the $\mathrm{NO}_{x}$ sensor film, an oxygen sensor is needed. There are several investigations on different resistive oxygen sensors that are suitable for harsh environmental conditions (Moos et al., 2011). Typically, resistive oxygen sensors are operated in a temperature range above $600^{\circ} \mathrm{C}$. In this range, the volume defect chemistry governs the charge carrier density in the material. Thermodynamics completely determine the concentration of charged point defects like oxygen vacancies or free electrons. The sensor temperature and the ambient oxygen concentration (i.e., the oxygen partial pressure) determine the defect concentration. At a sufficiently high temperature, the thermally activated processes of defect mobility and diffusion allow the metal oxide to interact rapidly with the surrounding gas atmosphere. An equilibrium is formed between the oxygen contained in the material and the oxygen molecules in the environment. Thus, at high oxygen partial pressure, the oxygen molecules are incorporated into the crystal lattice by filling up the oxygen vacancies and forming defect electrons. At low oxygen partial pressures, the process runs in the opposite direction. This leads to a change in the conductivity of the sensor material and can be detected as a change in its resistivity (Moseley, 1997; Moseley and Williams, 1989; Gerblinger et al., 1995; Schönauer, 1991; Tragut and Härdtl, 1991). Such selective resistive oxygen sensors should ideally only react to changes in oxygen concentration but not to changes in temperature. There are only a few materials that have a low or negligible temperature dependency, like $\mathrm{Co}_{1-x} \mathrm{Mg}_{x} \mathrm{O}$ (Park and Logothetis, 1977), $\mathrm{SrMg}_{0.4} \mathrm{Ti}_{0.6} \mathrm{O}_{3}$ (Yu et al., 1986), and $\mathrm{SrTi}_{0.65} \mathrm{Fe}_{0.35} \mathrm{O}_{3-\delta}$ (STF35) (Menesklou et al., 1999; Moos et al., 2003). Of these materials, STF has therefore been very thoroughly investigated as a temperature-independent oxygen sensor material from different groups (Menesklou et al., 1999; Moos et al., 2011; Rothschild et al., 2005). How- ever, it could be shown that STF has some problems with sulfur poisoning in real exhaust applications. The material is also unstable under rich conditions (Rettig et al., 2004). Further investigations on temperature-independent oxygen were carried out for sensors based on ceria using zirconia to compensate for the temperature dependency (Izu et al., 2005). Moseley and Williams (1989) therefore proposed barium iron tantalate $\mathrm{BaFe}_{1-x} \mathrm{Ta}_{x} \mathrm{O}_{3-\delta}$ (BFT) as a temperatureindependent resistive oxygen sensor material. BFT shows a fast and highly sensitive sensor response to changes in the ambient oxygen atmosphere, with fewer stability issues (Bektas et al., 2014a, b, 2018a, b). Because of that, barium iron tantalate was used as the oxygen sensor material in this study.

The present study combines both sensor principles on one single device (Bleicker et al., 2020). This allows one to manufacture a combined $\mathrm{O}_{2} / \mathrm{NO}_{x}$ sensor to be mounted in one position with almost no additional cost. To start with, laboratory measurements were conducted on each single element to reproduce previous results. Then, the sensor transducer was modified in a way that the $\mathrm{NO}_{x}$-sensitive as well as $\mathrm{O}_{2}$-sensitive layers are located together on one single platform, and both are connected with electrical feed lines. The sensing devices were then operated in a heated furnace to validate the basic functionality to measure both signals simultaneously with different electronic measuring devices. In the last step, a thick-film heater was integrated. It is located on the reverse side of the ceramic transducer to heat up both front-side-located sensors. This enables fully self-heated operation.

\section{Sensor setup and experimental details}

The sensor transducer is shown schematically in Fig. 1. It is made by using planar thick-film technology on alumina substrates (CeramTec $708 \mathrm{~S}$ ). On its front side, the measuring electrodes are located. They contact the sensor films. On its reverse side, a thick-film platinum heater is integrated for adjusting a constant operation temperature. Both sensing parts, the $\mathrm{NO}_{x}$-sensitive as well as oxygen-sensitive functional film, require a certain operating temperature to obtain their maximum sensitivity and stability. For this reason, a meander-shaped heater structure was applied to the reverse side of the substrate. This heating element is operated in a four-wire technique. The resistance in the area where both gas-sensing parts are located in the sensor tip is measured separately by two feed lines. Thus, the sensor tip can be brought to a constant operating temperature. Temperature adjustment is controlled by the temperature-dependent heater resistance itself, which has been calibrated before. For this calibration a sensor device was integrated in a tube furnace in air. The resistance of the sensor heater was measured with a digital multimeter (Keithley 2700 series) in the four-wire resistance mode. During the measurement the fur- 
(a)

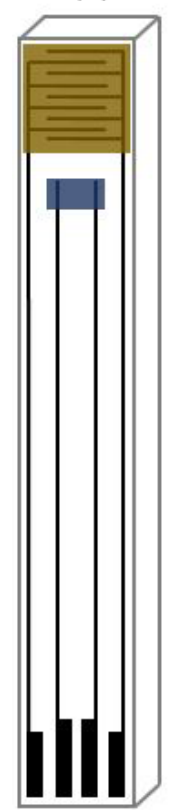

(b)

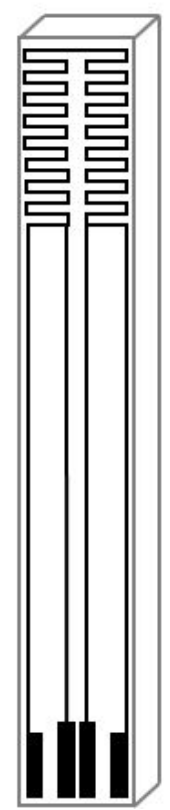

Figure 1. Scheme of the sensor setup (a: sensing side, b: reverse side of the sensor with heating element); image of the sensing side (c).

nace temperature was increased from room temperature to $750^{\circ} \mathrm{C}$. With this measurement it was possible to investigate the temperature-dependent characteristic curve of the heater in Eq. (1):

$\vartheta(R)=0.5404 \frac{{ }^{\circ} \mathrm{C}}{\Omega^{2}} \cdot R^{2}+33.454 \frac{{ }^{\circ} \mathrm{C}}{\Omega} \cdot R-222.48^{\circ} \mathrm{C}$,

where $R$ is the resistance of the heater and $\vartheta$ is the resulting temperature of the heater structure.

For all measurements, a lab setup to provide synthetic gas mixtures was used. In such a test bench, different gas flows are controlled by mass flow controllers. For an additional control of the adjusted gases, the signal of a wideband lambda probe type LSU 4.2 (Bosch) was recorded during all experiments.

\section{$2.1 \mathrm{NO}_{x}$ sensor film}

In the present work, the $\mathrm{NO}_{x}$ sensor film consisted of potassium permanganate $\left(\mathrm{KMnO}_{4}\right)$ supported on lanthanumstabilized $\gamma-\mathrm{Al}_{2} \mathrm{O}_{3}$. It was produced by the "incipient wetness impregnation" method (Marr, 2016; Groß, 2016; Roy and Baiker, 2009; Haukka et al., 1999). For this, potassium permanganate is dissolved in water and impregnated in several steps on lanthanum-stabilized $\gamma-\mathrm{Al}_{2} \mathrm{O}_{3}$ powder (3\% lanthanum content) as described in Marr (2016). Out of this powder, a screen-printable paste was produced to apply the gas-sensitive film as a thick film on top of also screen-printed electrode structures. Therefore, an interdigital layout with line $=$ space $=100 \mu \mathrm{m}$ (in an area of about $5 \times$ $5 \mathrm{~mm}$ ) was used. Electrodes were made of platinum and were also located on the front side of the transducers. Increasing $\mathrm{NO}_{x}$ concentrations admixed to the base gas led to decreasing impedance values. Impedance measurements were conducted at a constant frequency of $100 \mathrm{kHz}$ (HP 4284A, LCR-Meter). From each recorded impedance value (which is part of a "semi-circle" in the impedance representation in the complex plane), the resistance of the functional layer can be determined by means of magnitude $(|\underline{Z}|)$ and phase $(\varphi)$ as shown in Eq. (2):

$R=\frac{|\underline{Z}|}{\cos (\varphi)}$

When $\mathrm{NO}_{x}$ is added, the resistance of the $\mathrm{NO}_{x}$ sensor film decreases. For better comparison, data were evaluated as relative change in the resistance signal $\left(\Delta R / R_{0}\right)$. In this way the sensor signal increases with increasing $\mathrm{NO}_{x}$ concentration (Groß et al., 2013; Groß, 2016; Marr, 2016).

\section{$2.2 \mathrm{O}_{2}$ sensor film}

For the oxygen measurement, two additional platinum electrodes were applied on the front side in the space between the IDE feed lines. In contrast to former investigations (Bektas et al., 2014a, 2018a), a two-wire technique was used instead of a four-wire technique to derive the sensor resistance.

The oxygen sensor material barium iron tantalate $\left(\mathrm{BaFe}_{0.74} \mathrm{Al}_{0.01} \mathrm{Ta}_{0.25} \mathrm{O}_{3-\delta}\right.$, abbreviated as BFAT) was produced using the conventional mixed-oxide technique (Azad and Hon, 1998; Bonne et al., 2011). The starting materials were commercially available $\mathrm{BaCO}_{3}$ (Alfa Aesar, $99 \%$ ), $\mathrm{Fe}_{2} \mathrm{O}_{3}$ (Alfa Aesar, $98 \%$ ), $\mathrm{Al}_{2} \mathrm{O}_{3}$ (Almatis, CL3000, $99.8 \%$ ), and $\mathrm{Ta}_{2} \mathrm{O}_{5}$ (Alfa Aesar, 99\%). These powders were filled together with grinding tools and the grinding medium cyclohexane into $\mathrm{ZrO}_{2}$ milling bowls of a planetary ball mill. The mixture was ball-milled at $180 \mathrm{~min}^{-1}$ for $4 \mathrm{~h}$ and dried for $1 \mathrm{~d}$ at $200^{\circ} \mathrm{C}$. Afterwards the homogeneously mixed powder was calcined in a chamber furnace in air at $1350{ }^{\circ} \mathrm{C}$ for $15 \mathrm{~h}$. To further reduce the particle size, the powder was ballmilled again in the planetary ball mill and dried at $200^{\circ} \mathrm{C}$ for $1 \mathrm{~d}$. The powder was then sieved with $90 \mu \mathrm{m}$ meshes (Bektas et al., 2014a). Here also, the powder was processed to a screen-printable paste and applied as a thick film on top of the contacting electrodes. The oxygen-concentrationdependent resistance between the two electrodes was measured with a digital multimeter (Keithley 2700 series) in the dc mode.

\section{Preliminary tests}

\section{1 $\mathrm{NO}_{x}$ sensor film}

Figure 2 shows a first examination of the $\mathrm{NO}_{x}$-sensitive film. During the whole period the sensor was kept at a constant 
operating temperature of $650^{\circ} \mathrm{C}$ using the integrated heater. The sensor was exposed to a base gas that consisted of $15 \%$ $\mathrm{O}_{2}, 3 \% \mathrm{CO}_{2}$, and $3 \% \mathrm{H}_{2} \mathrm{O}$ with $\mathrm{N}_{2}$ as a balance. In the course of the tests, $\mathrm{NO}, \mathrm{CO}, \mathrm{NH}_{3}, \mathrm{H}_{2}, \mathrm{NO}_{2}$, or $\mathrm{C}_{3} \mathrm{H}_{8}$ were added in different concentration levels. In a second step, the base gas was changed to $5 \% \mathrm{O}_{2}, 8 \% \mathrm{CO}_{2}$, and $8 \% \mathrm{H}_{2} \mathrm{O}$ balanced by $\mathrm{N}_{2}$, and the mentioned gases were added again. The base gas compositions represent two typical lambda states occurring in real-world application. Since the existing oxygen concentration can be converted into lambda, the oxygen concentration is used for further consideration. In the upper half of the diagram in Fig. 2, the concentrations of the added gases are plotted over time. In the lower half, the oxygen concentration and the resulting measuring signal of the $\mathrm{NO}_{x}$ sensor film are shown. For better comparison, the data are normalized as relative change in the resistance signal $\left(\left|\Delta R / R_{0}\right|\right)$. For the base gas with a higher oxygen concentration $\left(15 \% \mathrm{O}_{2}, 3 \% \mathrm{CO}_{2}\right.$, and $\left.3 \% \mathrm{H}_{2} \mathrm{O}\right)$, the $\mathrm{NO}_{x}$ sensor signal responds to $\mathrm{NO}$ and $\mathrm{NO}_{2}$ admixture as known from Groß et al. (2013). As soon as $\mathrm{NO}$ or $\mathrm{NO}_{2}$ is added to the base gas, the sensor resistance decreases. However, a crosssensitivity to $\mathrm{NH}_{3}$ is visible as well. The sensitivity to $\mathrm{NH}_{3}$ is in a similar range to the sensitivity to $\mathrm{NO}$ or $\mathrm{NO}_{2} . \mathrm{CO}, \mathrm{H}_{2}$, or $\mathrm{C}_{3} \mathrm{H}_{8}$ do not interfere. If the oxygen concentration decreases, an increase in the signal of the $\mathrm{NO}_{x}$-sensitive film can be observed. The sensor response to $\mathrm{NO}, \mathrm{NO}_{2}$, and $\mathrm{NH}_{3}$ in that atmosphere with lower oxygen content $\left(5 \% \mathrm{O}_{2}\right)$ behaves similarly to in the previous base gas level. Even more, it can be seen that the sensitivity also decreases at lower oxygen levels. So, it is necessary to correct the $\mathrm{NO}_{x}$ results by secondary information about the actual oxygen concentration. One possibility is to derive data from another sensor device that might be installed anyway (e.g., lambda probe). Many applications might not give this opportunity, and it would generate additional costs. Ideally, the oxygen measurement takes place directly on the same sensor transducer as the $\mathrm{NO}_{x}$ measurement is carried out. Furthermore, a drift in the sensor signal can be observed, which may indicate that the operation temperature of the $\mathrm{NO}_{x}$ sensor film is too low. More details on the drift behavior are given in Sect. 4.2.

\subsection{Oxygen sensor film}

As indicated above, the BFAT oxygen sensor film was also investigated separately for a first characterization. These investigations were carried out by installing the sensor in a tube furnace utilizing a sample holder. Here, an $\mathrm{O}_{2}$ variation in $\mathrm{N}_{2}$ was carried out, with $10 \% \mathrm{O}_{2}$ in $\mathrm{N}_{2}$ representing the base level. At the used experimental setup, the gas feed lines are not heated, so it was not possible to add water to the base gas. The furnace heats both the test gas and the oxygen sensor to different operating temperatures, here 600,650, 700, and $750^{\circ} \mathrm{C}$. The obtained result data can be seen in Fig. 3, plotted as relative resistance changes over time, with $R_{0}$ being the resistance at $10 \%$ oxygen. At all temperatures, the

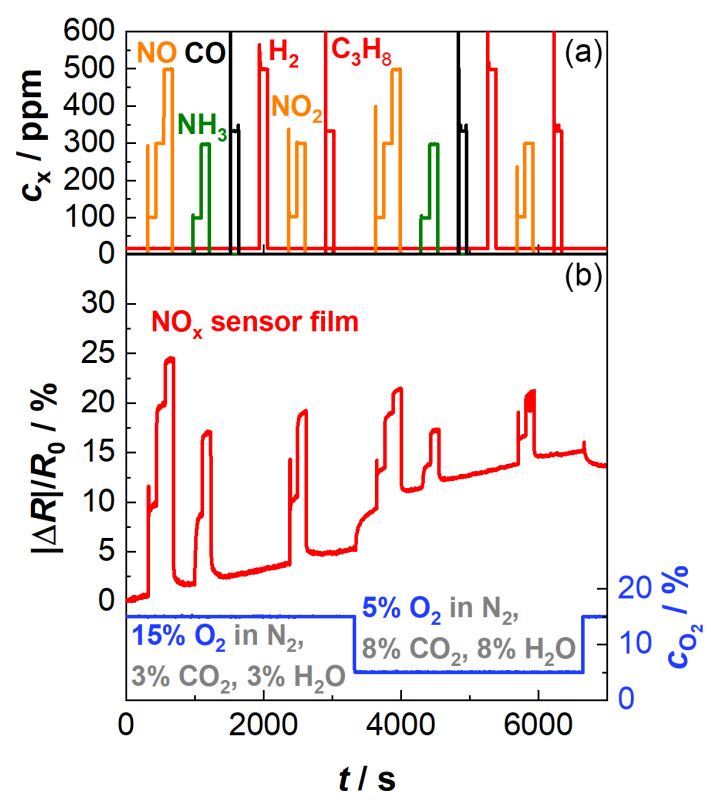

Figure 2. Sensor test procedure (a) and response of the $\mathrm{NO}_{x}$ sensor film (b) to $\mathrm{NO}, \mathrm{NH}_{3}, \mathrm{CO}, \mathrm{H}_{2}, \mathrm{NO}_{2}$, and $\mathrm{C}_{3} \mathrm{H}_{8}$; sensor temperature: $650{ }^{\circ} \mathrm{C}$; composition 1: $15 \% \mathrm{O}_{2}, 3 \% \mathrm{CO}_{2}, 3 \% \mathrm{H}_{2} \mathrm{O}$ balanced by $\mathrm{N}_{2}$ until $3700 \mathrm{~s}$; composition 2: $5 \% \mathrm{O}_{2}, 8 \% \mathrm{CO}_{2}, 8 \% \mathrm{H}_{2} \mathrm{O}$ balanced by $\mathrm{N}_{2}$ after $3700 \mathrm{~s}$.

sensor responds clearly and quickly to the target gas oxygen (please note that the sensor response and recovery times are limited by the test bench to at least $40 \mathrm{~s}$ ). The oxygen step closest to the real-world application in Fig. 3 is between $1 \%$ $\mathrm{O}_{2}$ and $10 \% \mathrm{O}_{2}$. Here, the sensor signal changes by $62 \%$. For comparison, a temperature change of $100^{\circ} \mathrm{C}$ results in a signal change of $6 \%$. Thus, the temperature dependency can be considered relatively low. The sensor signal reaches a stable final value for each oxygen level. For 600 and $650{ }^{\circ} \mathrm{C}$ the sensor response returns to its initial level, except when changing from pure oxygen to a lower level. However, this extreme case will not occur in real exhaust applications. This corresponds to the optimum operating temperature of $650^{\circ} \mathrm{C}$ for the $\mathrm{NO}_{x}$ sensor film. Thus, all subsequent measurements were carried out with a sensor temperature of $650^{\circ} \mathrm{C}$. In realworld applications, temperature fluctuations of the exhaust may cause small changes in the sensor temperature. In the active heating mode, the sensor temperature is controlled by a four-wire heater. The four-wire resistance of the heater indicates the temperature applied to the sensor and can therefore be used for mathematical temperature compensation.

\section{Multi-gas sensor test: results and discussion}

\subsection{Without integrated heater ("passively heated")}

In the second step, functional tests were carried out with sensor devices comprising both sensor films on one substrate. A sensor was installed in a tube furnace again to ensure the 


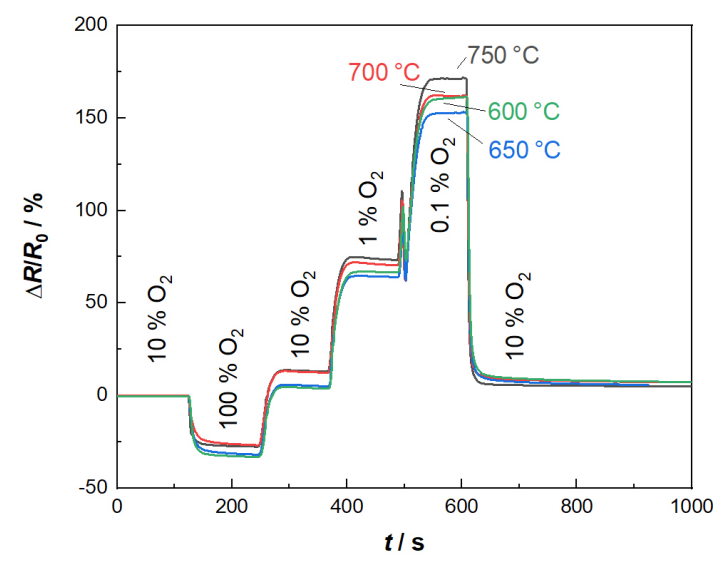

Figure 3. Response of the oxygen sensor film at different temperatures, heated by a tube furnace ("passively heated" sensor); $\mathrm{O}_{2}$ variation balanced in $\mathrm{N}_{2}: 0.1 \%, 1 \%, 10 \%, 100 \%$.

constant operating temperature of $650^{\circ} \mathrm{C}$. Starting with the base gas composition of $15 \% \mathrm{O}_{2}$ and $3 \% \mathrm{CO}_{2}$ (all balanced in $\mathrm{N}_{2}$ ), two additional base gas compositions (composition 2 : $7.5 \% \mathrm{O}_{2}$ and $6.5 \% \mathrm{CO}_{2}$; composition $3: 2 \% \mathrm{O}_{2}$ and $10 \%$ $\mathrm{CO}_{2}$ ) were investigated. To each of these three base gases, NO was added in three steps $(100,600,1200 \mathrm{ppm})$. Figure 4 shows the relative resistance changes in the $\mathrm{NO}_{x}$ sensor film (red) and the oxygen sensor film (black) over time. In the lower part of the diagram, the different gas compositions are shown by means of their oxygen concentration. The oxygen sensor film responds in a stable manner to the changing oxygen concentrations. Also, no cross-sensitivity towards NO can be detected. Likewise, the base level from the beginning of the test (at $15 \%$ oxygen) is also reached again at the end after approximately $4000 \mathrm{~s}$. From the impedance of the $\mathrm{NO}_{x}$ sensor film, the NO levels are clearly reflected, not depending on the base gas compositions. As in the previous measurements, the sensitivity of the $\mathrm{NO}_{x}$ response decreases with decreasing oxygen concentration. Both data sets show low noise. This verifies the possibility of integrating an impedance-based and a dc-resistance-based measurement within one device without electrical interferences.

\subsection{Self-heated device ("actively heated")}

The final step was to realize a stand-alone device by utilizing the integrated heater for temperature control and operate the sensor as a self-heated device. For this purpose, a complete transducer (as introduced in Fig. 1), comprising both sensor films on the front side and also the heater on the reverse side, was mounted in a gas-tight stainless-steel housing. Four connections on each side of the substrate were made by clamping in a sensor holder. This device was integrated into a $120^{\circ} \mathrm{C}$ heated chamber, so that no water could condense, and then exposed to different gases $\left(\mathrm{NO}, \mathrm{NH}_{3}\right.$, $\mathrm{CO}, \mathrm{H}_{2}, \mathrm{NO}_{2}$, and $\mathrm{C}_{3} \mathrm{H}_{8}$ ) in two different base gas composi-

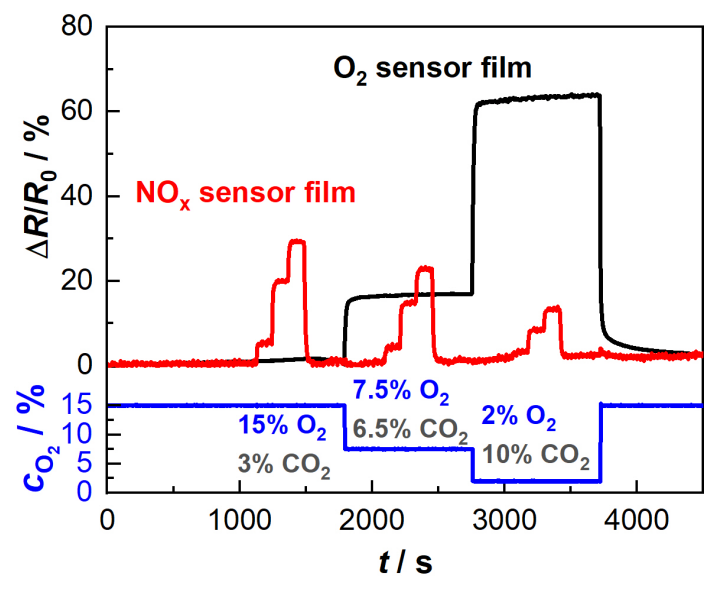

Figure 4. Initial test of the multi-gas sensor consisting of the $\mathrm{NO}_{x}$ sensor film and the BFAT oxygen sensor film, heated by a tube furnace at $650{ }^{\circ} \mathrm{C}$ ("passively heated" sensor); NO variation $(100,600$, $1200 \mathrm{ppm}$ ) at three different compositions: composition 1: $15 \% \mathrm{O}_{2}$ and $3 \% \mathrm{CO}_{2}$; composition 2: $7.5 \% \mathrm{O}_{2}$ and $6.5 \% \mathrm{CO}_{2}$; composition 3: $2 \% \mathrm{O}_{2}$ and $10 \% \mathrm{CO}_{2}$, all balanced in $\mathrm{N}_{2}$.

tions (composition 1: $15 \% \mathrm{O}_{2}, 3 \% \mathrm{CO}_{2}, 3 \% \mathrm{H}_{2} \mathrm{O}$, balanced by $\mathrm{N}_{2}$; composition 2: $5 \% \mathrm{O}_{2}, 8 \% \mathrm{CO}_{2}, 8 \% \mathrm{H}_{2} \mathrm{O}$, balanced by $\mathrm{N}_{2}$ ). The sensor operation temperature of $650^{\circ} \mathrm{C}$ was provided by the reverse side heater using Eq. (1).

Results are shown in Fig. 5. In the upper part of the diagram, the concentrations of the added gases are given. The lower part of the diagram shows the relative resistance change in the $\mathrm{NO}_{x}$ sensor film (red) and the oxygen sensor film (black). In addition, the oxygen concentration (blue), measured by a wideband lambda probe type LSU 4.2 (Bosch), is also given. The $\mathrm{NO}_{x}$ sensor film shows the expected response towards $\mathrm{NO}$ and $\mathrm{NO}_{2}$ as in the previous tests. Also, the cross-sensitivity to $\mathrm{NH}_{3}$ can be seen again. In addition, the sensor baseline resistance increases, and the sensitivity of the $\mathrm{NO}_{x}$ sensor film decreases with decreasing oxygen concentration. It is possible, however, that the change in the baseline resistance is not caused by the change in the oxygen concentration but rather by the simultaneous increase in water content. Groß (2016) showed that at high sensor temperatures (about $420^{\circ} \mathrm{C}$ ) water competes with $\mathrm{NO}_{x}$ for the storage spaces and thus leads to a decrease in resistance, but this has to be studied more in detail in future investigations. Furthermore, it is shown again that further components of the exhaust $\left(\mathrm{CO}, \mathrm{H}_{2}\right.$, and $\left.\mathrm{C}_{3} \mathrm{H}_{8}\right)$ do not affect the sensor response. Concerning the oxygen sensor film, the influence of oxygen is clearly visible (black). Additionally, an existing but very low cross-sensitivity to $\mathrm{NO}_{2}$ can be recognized. Older studies of BFAT showed that BFAT becomes sensitive to gases like $\mathrm{NO}$ and $\mathrm{NO}_{2}$ if the sensor temperature is too low (Bektas et al., 2014a). However, the effect is different for both base gas compositions (increasing at higher oxygen concentration and decreasing at lower oxygen concentration) and is yet understood. Moreover, a drift behavior of both sen- 


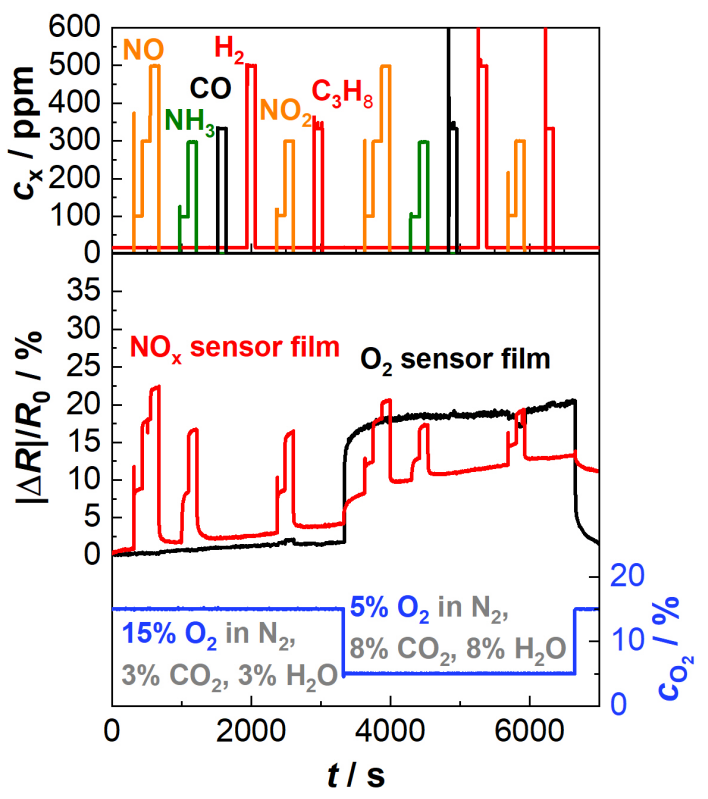

Figure 5. Sensor response of the actively heated $\mathrm{NO}_{x}$ sensor film (red) and the oxygen sensor film (black) of a multi-gas sensor to $\mathrm{NO}, \mathrm{NH}_{3}, \mathrm{CO}, \mathrm{H}_{2}, \mathrm{NO}_{2}$, and $\mathrm{C}_{3} \mathrm{H}_{8}$; sensor temperature: $650{ }^{\circ} \mathrm{C}$; composition 1: $15 \% \mathrm{O}_{2}, 3 \% \mathrm{CO}_{2}, 3 \% \mathrm{H}_{2} \mathrm{O}$ balanced by $\mathrm{N}_{2}$ until 3700 s; composition 2: $5 \% \mathrm{O}_{2}, 8 \% \mathrm{CO}_{2}, 8 \% \mathrm{H}_{2} \mathrm{O}$ balanced by $\mathrm{N}_{2}$ after $3700 \mathrm{~s}$.

sor signals is noticeable over the whole measurement. This also indicates that the sensor temperature may be too low. The sensor temperature is set by the heater on the reverse side of the sensor. Due to flow effects and heating losses, the temperature at the sensing part is lower than on the heating side. As explained in Sect. 1, the sensor films have to be operated in a temperature range above $600^{\circ} \mathrm{C}$. If the temperature of the $\mathrm{O}_{2}$ sensor film is too low, the sensor responds more slowly to the ambient gas atmosphere, as described in Sect. 1. This may cause a drift behavior of the $\mathrm{O}_{2}$ sensor film. At the $\mathrm{NO}_{x}$ sensor film, on the other hand, too low temperatures lead to a slower desorption of the nitrogen oxides from the gas-sensitive materials. This would explain a drift in the $\mathrm{NO}_{x}$ sensor response. To keep the temperature at a higher level, changes in the heater design will be tested.

\section{Correction of the $\mathrm{NO}_{x}$ signal using simultaneous $\mathrm{O}_{2}$ measurement results}

The integrated oxygen sensor film allows for correction of the influence of the oxygen concentration on the $\mathrm{NO}_{x}$ sensor response. For this purpose, a detailed characteristic curve of the oxygen sensor film at a sensor temperature of $650^{\circ} \mathrm{C}$ was recorded in synthetic exhaust gas only consisting of oxygen and $\mathrm{N}_{2}$. As can be seen in Fig. 6, the correlation between resistance change and oxygen concentration can be approximated by a second-degree polynomial in Eq. (3):

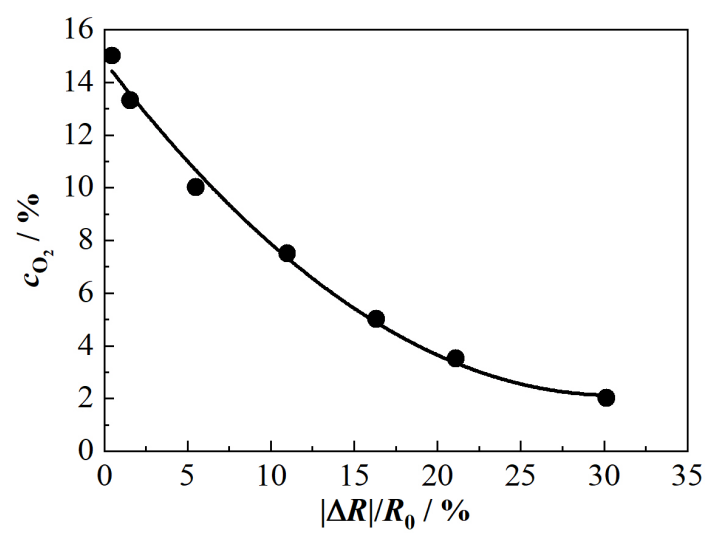

Figure 6. Characteristic curve of the $\mathrm{O}_{2}$-sensitive functional layer; sensor temperature: $650{ }^{\circ} \mathrm{C} ; \mathrm{O}_{2}$ variation balanced by $\mathrm{N}_{2}: 2 \%$, $3.5 \%, 5 \%, 7.5 \%, 10 \%, 13.5 \%$, and $15 \%$.

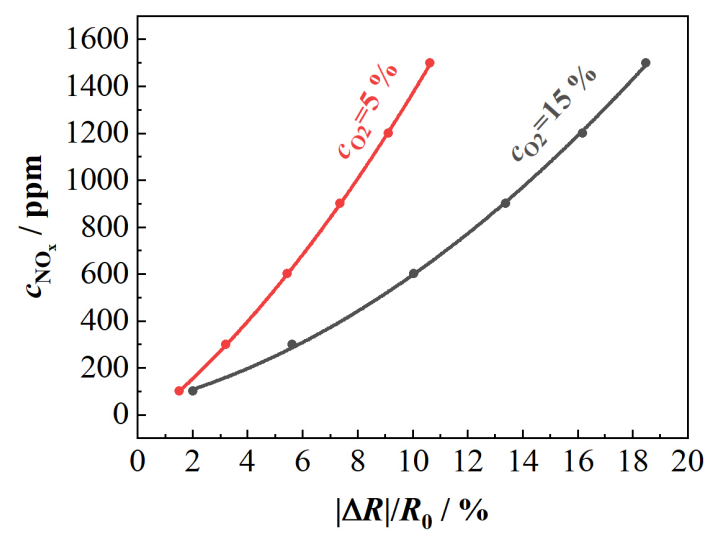

Figure 7. NO characteristic curve of the NO-sensitive layer for different oxygen concentrations; sensor temperature: $650^{\circ} \mathrm{C}$; composition 1: $15 \% \mathrm{O}_{2}, 3 \% \mathrm{CO}_{2}, 3 \% \mathrm{H}_{2} \mathrm{O}$ balanced by $\mathrm{N}_{2}$; composition 2: $5 \% \mathrm{O}_{2}, 8 \% \mathrm{CO}_{2}, 8 \% \mathrm{H}_{2} \mathrm{O}$ balanced by $\mathrm{N}_{2}$; $\mathrm{NO}$ variation: $100,300,600,900,1200,1500 \mathrm{ppm}$.

$c_{\mathrm{O}_{2}}\left(\frac{|\Delta R|}{R_{0}}\right)=14.81 \%-0.83 \cdot \frac{|\Delta R|}{R_{0}}+0.013 \frac{1}{\%} \cdot\left(\frac{|\Delta R|}{R_{0}}\right)^{2}$.

This calibration curve enables us to determine the oxygen concentration from the sensor signal. Such characteristic curves at a sensor temperature of $650{ }^{\circ} \mathrm{C}$ were also taken for the $\mathrm{NO}_{x}$ sensor film. Here the $\mathrm{NO}$ concentration was varied between 100, 300, 600, 900, 1200, and $1500 \mathrm{ppm}$ for two gas compositions with different oxygen concentrations (composition 1: $15 \% \mathrm{O}_{2}, 3 \% \mathrm{CO}_{2}, 3 \% \mathrm{H}_{2} \mathrm{O}$; composition 2: $5 \%$ $\mathrm{O}_{2}, 8 \% \mathrm{CO}_{2}, 8 \% \mathrm{H}_{2} \mathrm{O}$; both compositions are balanced by $\mathrm{N}_{2}$ ). The results are shown in Fig. 7. Again, the dependency of the sensitivity towards $\mathrm{NO}_{x}$ on the oxygen concentration becomes clear. The characteristic curves of the $\mathrm{NO}_{x}$ sensor can also be expressed by second-degree polynomials. The characteristic curves for $15 \%$ and $5 \%$ oxygen are shown as examples. The characteristic curve for base gas with $15 \% \mathrm{O}_{2}$ 


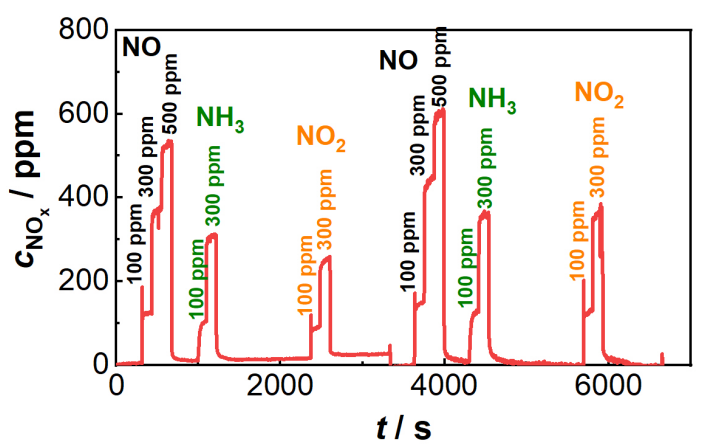

Figure 8. Resulting sensor signal after application of the characteristic curve correction; sensor temperature: $650{ }^{\circ} \mathrm{C}$; concentrations of the dosed gases $\mathrm{NO}(100,300,500 \mathrm{ppm}), \mathrm{NO}_{2}(100 \mathrm{ppm}$, $300 \mathrm{pm}$ ), and $\mathrm{NH}_{3}(100 \mathrm{ppm}, 300 \mathrm{pm})$ added in the diagram; composition 1: $15 \% \mathrm{O}_{2}, 3 \% \mathrm{CO}_{2}, 3 \% \mathrm{H}_{2} \mathrm{O}$ balanced by $\mathrm{N}_{2}$ until 3700 s; composition 2: $5 \% \mathrm{O}_{2}, 8 \% \mathrm{CO}_{2}, 8 \% \mathrm{H}_{2} \mathrm{O}$ balanced by $\mathrm{N}_{2}$ after $3700 \mathrm{~s}$.

is given by Eq. (4):

$$
\begin{aligned}
c_{\mathrm{NO}_{x}}\left(\frac{|\Delta R|}{R_{0}}\right) & =39.45 \mathrm{ppm}+28.64 \frac{\mathrm{ppm}}{\%} \cdot \frac{|\Delta R|}{R_{0}} \\
& +2.70 \frac{\mathrm{ppm}}{\%^{2}} \cdot\left(\frac{|\Delta R|}{R_{0}}\right)^{2} .
\end{aligned}
$$

For an oxygen concentration of $5 \%$, the characteristic curve is represented by Eq. (5):

$$
\begin{aligned}
c_{\mathrm{NO}_{x}}\left(\frac{|\Delta R|}{R_{0}}\right) & =-50.67 \mathrm{ppm}+92.43 \frac{\mathrm{ppm}}{\%} \cdot \frac{|\Delta R|}{R_{0}} \\
& +4.97 \frac{\mathrm{ppm}}{\%^{2}} \cdot\left(\frac{|\Delta R|}{R_{0}}\right)^{2} .
\end{aligned}
$$

When the coefficients of the polynomials from Eqs. (4) and (5) as well as other $\mathrm{NO}_{x}$ characteristic curves for fixed oxygen concentrations are plotted as a function of the oxygen concentration, the results are second-degree oxygendependent polynomials. The coefficients in Eqs. (4) or (5) can thus be represented as a second-degree polynomial, which is dependent on the oxygen concentration. So it is possible to replace both equations with a second-degree polynomial with oxygen-dependent coefficients. Due to the drift behavior in Fig. 5, a linear adjustment of the base level was additionally carried out by determining the slope between the first measurement point and the last measurement point at the higher oxygen concentration. The same procedure was used for the lower oxygen concentration, so the drift behavior could be corrected here as well. The described correction of the sensor behavior is applied to the signals shown in Fig. 5. The sensor signal is converted directly into a $\mathrm{NO}_{x}$ concentration. The result of the correction can be seen in Fig. 8. It can be seen that the influence on the oxygen concentrationdependent decrease in the sensitivity of the $\mathrm{NO}_{x}$ sensor signal is much less pronounced.

\section{Conclusion and outlook}

It was shown that two different sensors working with different operation principles can be integrated on one sensor platform. Both the separate and simultaneous operations of the functional layers were demonstrated. Even self-heating by a reverse side heater is possible without influencing the simultaneous measurement. The presented $\mathrm{NO}_{x}$ sensing device shows a characteristic which depends on the ambient oxygen concentration. By the simultaneous operation of both functional layers it is possible to correct this influence and enhance the $\mathrm{NO}_{x}$ sensor's performance. In further investigations the reasons for the observed drift behavior of both sensor signals have to be found out. Therefore, the influence of the sensor temperature and the influence of temperature homogeneity on the sensor signal will be investigated. Also, the influence of water will be tested in further studies.

Data availability. All relevant data presented in the article are stored according to institutional requirements and, as such, are not available online. However, all data used in this paper can be made available upon request to the authors.

Author contributions. RM, GH, FN, and DB created the concept of the project and were responsible for funding acquisition. Methodology was developed by $\mathrm{JH}, \mathrm{GH}$, and JK in close discussion with RM, FN, and DB. JH constructed the setup, conducted the investigation process, and wrote the original draft. All the authors contributed to the interpretation of the data and to the review and editing of the final paper. RM supervised the work.

Competing interests. The authors declare that they have no conflict of interest.

Special issue statement. This article is part of the special issue "Dresden Sensor Symposium DSS 2019". It is a result of the “14. Dresdner Sensor-Symposium”, Dresden, Germany, 2-4 December 2019.

Acknowledgements. The authors thank Angelika Mergner for her assistance by producing screen-printable pastes and Simon Püls for preparing the BFAT powder.

Financial support. This open-access publication was funded by the University of Bayreuth.

Review statement. This paper was edited by Thomas Scheper and reviewed by two anonymous referees. 


\section{References}

Azad, A.-M. and Hon, N. C.: Characterization of $\mathrm{BaSnO}_{3}-$ based ceramics. Part 1. Synthesis, processing and microstructural development, J. Alloy. Compd., 270, 95-106, https://doi.org/10.1016/S0925-8388(98)00370-3, 1998.

Bektas, M., Hanft, D., Schönauer-Kamin, D., Stöcker, T., Hagen, G., and Moos, R.: Aerosol-deposited $\mathrm{BaFe}_{0.7} \mathrm{Ta}_{0.3} \mathrm{O}_{3-\delta}$ for nitrogen monoxide and temperature-independent oxygen sensing, J. Sens. Sens. Syst., 3, 223-229, https://doi.org/10.5194/jsss-3223-2014, 2014a.

Bektas, M., Schönauer-Kamin, D., Hagen, G., Mergner, A., Bojer, C., Lippert, S., Milius, W., Breu, J., and Moos, R.: $\mathrm{BaFe}_{1-x} \mathrm{Ta}_{x} \mathrm{O}_{3-\delta}-\mathrm{A}$ material for temperature independent resistive oxygen sensors, Sensor. Actuat. B, 190, 208-213, https://doi.org/10.1016/j.snb.2013.07.106, 2014b.

Bektas, M., Püls, S., Hagen, G., and Moos, R.: Resistiver Sauerstoffsensor mit temperaturunabhängiger Kennlinie, in: Sensoren und Messsysteme 2018, 26.-27. Juni 2018, Nürnberg, 77-79, ISBN 978-3-8007-4683-5, 2018a.

Bektas, M., Stöcker, T., Hagen, G., and Moos, R.: On the defect chemistry of $\mathrm{BaFe}_{0.89} \mathrm{Al}_{0.01} \mathrm{Ta}_{0.1} \mathrm{O}_{3-\delta}$, a material for temperature independent resistive and thermoelectric oxygen sensors, Solid State Ion., 316, 1-8, https://doi.org/10.1016/j.ssi.2017.12.017, 2018b.

Bleicker, D., Noack, F., Costa, L., and Rühl, S.: $\mathrm{NO}_{x}$-Sensor für Nfz und mobile Maschinen, ATZ, 01/2020, Springer Fachmedien Wiesbaden GmbH, Wiesbaden, 38-41, 2020.

Bonne, M., Sellam, D., Dacquin, J.-P., Lee, A. F., Wilson, K., Olivi, L., Cognigni, A., Marécot, P., Royer, S., and Duprez, D.: A general route to synthesize supported isolated oxide and mixedoxide nanoclusters at sizes below $5 \mathrm{~nm}$, Chem. Commun., 47, 1509-1511, https://doi.org/10.1039/c0cc02662j, 2011.

Deutschmann, O. and Grunwaldt, J.-D.: Abgasnachbehandlung in mobilen Systemen: Stand der Technik, Herausforderungen und Perspektiven, Chem.-Ing.-Tech., 85, 595-617, https://doi.org/10.1002/cite.201200188, 2013.

Gerblinger, J., Hausner, M., and Meixner, H.: Electric and Kinetic Properties of Screen-Printed Strontium Titanate Films at High Temperatures, J. Am. Ceram. Soc., 78, 1451-1456, https://doi.org/10.1111/j.1151-2916.1995.tb08836.x, 1995.

Groß, A., Beulertz, G., Marr, I., Kubinski, D. J., Visser, J. H., and Moos, R.: Dual mode $\mathrm{NO}_{x}$ sensor: measuring both the accumulated amount and instantaneous level at low concentrations, Sensors, 12, 2831-2850, https://doi.org/10.3390/s120302831, 2012.

Groß, A., Kremling, M., Marr, I., Kubinski, D. J., Visser, J. H., Tuller, H. L., and Moos, R.: Dosimeter-type $\mathrm{NO}_{x}$ sensing properties of $\mathrm{KMnO}_{4}$ and its electrical conductivity during temperature programmed desorption, Sensors, 13, 4428-4449, https://doi.org/10.3390/s130404428, 2013.

Groß, A.: Einfluss von $\mathrm{NO}_{x}$ auf die elektrische Leitfähigkeit von $\mathrm{NO}_{x}$-Speichermaterialien und die Anwendung dieser Materialien für neuartige $\mathrm{NO}_{x}$-Dosimeter, Dissertation, Shaker Verlag $\mathrm{GmbH}$, Aachen, 2016.

Hagen, G., Müller, A., Lattus, J., Kita, J., Moos, R., Noack, F., and Bleicker, D.: Impedanz-basierter $\mathrm{NO}_{x}$-Sensor für Abgasanwendungen, in: Proceedings of Sensoren und Messsysteme 2019, 2.4.4, 25.-26. Juni 2019, Nürnberg, 197-200, https://doi.org/10.5162/sensoren2019/2.4.4, 2019.
Haukka, S., Lakomaa, E.-L., and Suntola, T.: Adsorption controlled preparation of heterogeneous catalysts, Stud. Surf. Sci. Catal., 120, 715-750, https://doi.org/10.1016/S0167-2991(99)80570-9, 1999.

Izu, N., Shin, W., Matsubara, I., Murayama, N., Oh-hori, N., and Itou, M.: Temperature independent resistive oxygen sensors using solid electrolyte zirconia as a new temperature compensating material, Sensor. Actuat. B, 108, 216-222, https://doi.org/10.1016/j.snb.2004.11.034, 2005.

Lattus, J., Hagen, G., Kita, J., Moos, R., Bleicker, D., and Noack, F.: $\mathrm{NO}_{x}$ sensor for exhaust applications, in: The 17th International Meeting on Chemical Sensors, IMCS 17, 15-19 July 2018, Vienna, Austria, 438-439, https://doi.org/10.5162/IMCS2018/P1AP.2, 2018.

Marr, I.: Materialien für dosimeterartige Gassensoren zur Detektion im ppm- und Sub-ppm-Bereich, Dissertation, Shaker Verlag $\mathrm{GmbH}$, Aachen, 2016.

Marr, I. and Moos, R.: Resistive $\mathrm{NO}_{x}$ dosimeter to detect very low $\mathrm{NO}_{x}$ concentrations - Proof-of-principle and comparison with classical sensing devices, Sensor. Actuat. B, 248, 848-855, https://doi.org/10.1016/j.snb.2016.12.112, 2017.

Menesklou, W., Schreiner, H.-J., Härdtl, K. H., and Ivers-Tiffée, E.: High temperature oxygen sensors based on doped $\mathrm{SrTiO}_{3}$, Sensor. Actuat. B, 59, 184-189, https://doi.org/10.1016/S09254005(99)00218-X, 1999.

Moos, R., Rettig, F., Hürland, A., and Plog, C.: Temperatureindependent resistive oxygen exhaust gas sensor for lean-burn engines in thick-film technology, Sensor. Actuat. B, 93, 43-50, https://doi.org/10.1016/S0925-4005(03)00333-2, 2003.

Moos, R., Izu, N., Rettig, F., Reiss, S., Shin, W., and Matsubara, I.: Resistive oxygen gas sensors for harsh environments, Sensors, 11, 3439-3465, https://doi.org/10.3390/s110403439, 2011.

Moseley, P. T.: Solid state gas sensors, Meas. Sci. Technol., 8, 223237, https://doi.org/10.1088/0957-0233/8/3/003, 1997.

Moseley, P. T. and Williams, D. E.: Gas sensors based on oxides of early transition metals, Polyhedron, 8, 1615-1618, https://doi.org/10.1016/S0277-5387(00)80606-3, 1989.

Park, K. and Logothetis, E. M.: Oxygen sensing with $\mathrm{Co}_{1-x} \mathrm{Mg}_{x} \mathrm{O}$ ceramics, ECS J. Solid State Sci. Technol., 124, 1443, https://doi.org/10.1149/1.2133671, 1977.

Rettig, F., Moos, R., and Plog, C.: Poisoning of Temperature Independent Resistive Oxygen Sensors by Sulfur Dioxide, J. Electroceram., 13, 733-738, https://doi.org/10.1007/s10832-004-5184$\mathrm{x}, 2004$.

Rothschild, A., Litzelman, S. J., Tuller, H. L., Menesklou, W., Schneider, T., and Ivers-Tiffée, E.: Temperature-independent resistive oxygen sensors based on $\mathrm{SrTi}_{1-x} \mathrm{Fe}_{x} \mathrm{O}_{3-\delta}$ solid solutions, Sensor. Actuat. B, 108, 223-230, https://doi.org/10.1016/j.snb.2004.09.044, 2005.

Roy, S. and Baiker, A.: $\mathrm{NO}_{x}$ storage-reduction catalysis: from mechanism and materials properties to storagereduction performance, Chem. Rev., 109, 4054-4091, https://doi.org/10.1021/cr800496f, 2009.

Schönauer, U.: Response times of resistive thick-film oxygen sensors, Sensor. Actuat. B, 4, 431-436, https://doi.org/10.1016/0925-4005(91)80147-C, 1991.

Tragut, C. and Härdtl, K. H.: Kinetic behaviour of resistive oxygen sensors, Sensor. Actuat. B, 4, 425-429, https://doi.org/10.1016/0925-4005(91)80146-B, 1991. 
van Basshuysen, R. (Ed.): Handbuch Verbrennungsmotor. Grundlagen, Komponenten, Systeme, Perspektiven, 1. Edn., Vieweg (ATZ/MTZ-Fachbuch), Braunschweig, 2002.

Yao, H. C. and Shelef, M.: The surface interaction of $\mathrm{O}_{2}$ and NO with manganous oxide, J. Catal., 31, 377-383, https://doi.org/10.1016/0021-9517(73)90308-4, 1973.
Yu, C., Shimizu, Y., and Arai, H.: Investigation on a lean-burn oxygen sensor using perovskite-type oxides, Chem. Lett., 15, 563566, https://doi.org/10.1246/cl.1986.563, 1986. 